\title{
6 Die Afrika-mensbeskouing (harmoniemodel)
}

Dit spreek haas vanself dat dit nie ons bedoeling is om hier enigsins ' $n$ volledige weergawe van die tradisionele Afrika-mensbeskouing te probeer gee nie. Wel sal gepoog word om die hoofkenmerke van hierdie antropologie weer te gee en krities te evalueer, natuurlik in die besef van die immer aanwesige gevaar van veralgemening ten opsigte van 'n 'Afrika'-mensbeskouing (Pretorius, 1977:5). Dit verander natuurlik niks aan die feit dat daar tog ' $n$ bepaalde eenheidslyn in die Afrika-denke merkbaar is sodat Banana (1991:22) kan opmerk dat Afrika slegs één tradisionele religie met verskillende uitwaaierings ken.

Tereg merk Pretorius (1977:14) op dat dit nie moontlik is om enige aspek van die lewe van die Afrikaan na behore te waardeer en te begryp nie "voordat iemand die kosmologie van die Swartman minstens ten dele ken en verstaan".

In wat volg, gaan gepoog word om die hoofmomente van die Afrika-mensbeskouing uit te lig soos dit ten nouste met die Afrika-kosmologie (en -teologie) saamhang en in 'n groot mate eintlik daarmee saanval (vgl. Wiredu, 1980:1-25).

\subsection{Kenmerke van die Afrika-mensbeskouing}

\section{* Religieusiteit}

Die Afrikaan beskou religie nie as déél van die lewe nie; nee, religie is lewe (Buthelezi, 1987:95). By die Afrikaan leef daar 'n sterk godsbesef asook die geloof dat God die mens geskape het, al is daar verskil oor die hoe daarvan (Mbiti, 1970:161-170). Hierdie tradisionele God of opperwese word dikwels gesien as die hoogste krag, wat dan in volle harmonie verkeer met die geesteswêreld (veral voorouergeeste), daana met die mensewêreld en vervolgens met die natuurwêreld. Geloof in God/gode, geeste, voorvadergeeste en magie is nie net ' $n$ veel voorkomende verskynsel nie, maar is inderdaad wesentlik deel van die lewe, ja, is die lewe (Oosthuizen, 1978:269 e.v.; Van Rooy, 1978:12 e.v.; Van der Walt, 1990:26).

Die Afrika-mensbeskouing is ' $\mathrm{n}$ deur en deur religieuse mensbeskouing (homo religiosus).

\section{* Totaliteit}

Die kosmologie - en antropologie - van Afrika is holisties en dus vreemd aan die dualismes wat so kenmerkend van die Westerse denke is. Die natuur, die mens 
en die Onsigbare vorm 'n onlosmaaklike eenheid en die mens se welsyn bestaan daarin dat hy met hierdie totaliteit in harmonie leef (Pretorius, 1977:7). Die lewe vorn ' $n$ onuitrafelbare eenheid en sluit selfs eenheid (kontak) tussen lewendes en 'dooies' in (waaroor weldra meer) (Buthelezi, 1973:99-100; Van der Walt, 1988: 7, 1990:28). Die bekende Westerse dualismes - sekulêr/sakraal, reëel/spiritueel, vertikaal/horisontaal, lewende/dooie, individu/gemeenskap, siel/liggaam, ortodoksie/ortopraksie - is aan die Afrika-denke vreemd. Die diversiteit (byvoorbeeld kerk en wêreld) word wel nie ontken nie maar die perspektief van eenheid ('n lewe coram Deo) oorheers (Buthelezi, 1973:100). Geen wonder dus dat vanuit hierdie holistiese pespektief skerp kritiek teen die 'tradisionele Westerse teologie' (waaronder Augustinus, Luther en Calvyn) uitgespreek is - origens nie sonder dat die 'Westerse teologie' soms erg verteken is nie. So kritiseer Maimela (1991:10) die Westerse teologie omdat dit die evangelie gespiritualiseer en geïndividualiseer het. Volgens Maimela het die Westerse teologie ook die sonde en verlossing vereng en daarom moet daar wegbeweeg word van 'n individualistiese na 'n meer holistiese verlossingsleer (Maimela, 1991:10-13).

Afrika sien die mens en die lewe as een groot geheel.

\section{* Vitaliteit}

Krag en lewenskrag is van bepalende betekenis en die motief om lewenskrag te beskerm, te versterk en te vergroot, lê ten grondslag aan byna alle praktyke van die Afrikaan (Pretorius, 1977:8). Daar is 'n hele hiërargie van magte - vanaf God na die gode/geeste, na die voorvadergeeste, na die mense (konings, pa's, oudste seun), na diere, plante en dooie stof - en welsyn beteken niks anders as om in hierdie hiêrargie goed geïntegreer te wees nie (Van Rooy, 1978:3-7; Van der Walt, 1988:7; 1990:26, 28). Hierdie siening maak bemiddelaars noodsaaklik en lei maklik tot 'n statiese beskouing van die samelewing en tot 'n gebrek aan private inisiatief. Senioriteit en paternalisme ontvang ' $n$ buitengewone swaar aksent (Van der Walt, 1990:51).

\section{* Kommuniteit}

Die motief van gemeenskap is een van die mees basiese - en waarskynlik een van die mees waardevolle - kenmerke van die mensbeskouing van die Afrikaan (Setiloane, 1986:51, 54; Van der Walt, 1990:32, 34, 36, 47, 48). Tereg sê Menkiti (1984:171) dat "man is defined by reference to the environing community" en dat die groot verskil tussen die Afrika- en Westerse mensbeskouings daarin geleë is dat "in the African view it is the community which defines the person as person, not some isolated static quality of rationality, will or memory" (Menkiti, 1984:172). Die Afrikaan se benadering is kollektivisties - dit beweeg van die gemeenskap na die individu - terwyl die benadering van die Westerling atomis- 
ties is - en beweeg (nee, dit moet georganiseer word) van die individu na die gemeenskap (Menkiti, 1984:179-180). Die bekende spreuk, wat wydverbreid in Afrika aangetref word, lui: 'n mens is 'n mens deur sy medemens (vgl. Mbiti, 1970:14; Pretorius, 1977:12; Oosthuizen, 1978:281; Van der Walt, 1988:9). Een van die grootste euwels is dan ook geleë in die afbraak van die stabiliteit van die gemeenskap (Maimela, 1991:8); sonde is eerstens sonde teen die gemeenskap, dan teen die voorouergeeste en laastens teen die Opperwese. Dis 'n baie groot sonde om teen die groep te oortree en dis vir 'n Afrikaan bitter moeilik om alleen - en teen die groep in - vir die waarheid te getuig (Van der Walt, 1990:48, met verwysing na Adeyemo; Van der Walt, 1988:12-13).

Conduct that promotes smooth relationships, that upholds the social structure, is good; conduct that runs counter to smooth relations, is bad. Courtesy and respect due to age or seniority are thus of greater importance than truth (Van Rooy, 1978:10).

Geen wonder dat die Afrikaan gekenmerk word deur karaktertrekke wat gemeenskap bevorder - karaktertrekke soos vriendelikheid, beleefdheid, aanpasbaarheid, buigsaamheid, inskiklikheid, beskeidenheid, nederigheid, gesagserkenning en (veral) mededeelsaamheid (Van Rooy, 1978:10; Van der Walt, 1988:10-11; 1990:46-47). Mededeelsaamheid is 'n deug wat van jongsaf ingeprent word en Shonakinders word van kleinsaf geleer om kos te deel (Banana, 1991:82-83); in Venda is daar ' $n$ gesegde wat lui dat 'die kinders van een pa selfs die kop van 'n sprinkaan verdeel' (Van Rooy, 1978:11). Lewe is lewe-in-partisipasie.

Dit is dus begryplik dat kommunikasie en dialoog (en konsensus) so 'n belangrike rol in Afrika speel.

Hierdie kommuniteit bestaan egter nie net in die hede tussen die lewendes nie maar gryp ook terug na die 'dooies' (soos ons weldra sal sien); ja, strek ook vooruit na die nog-nie-lewendes. Kommunikasie vind in alle tydskategoriee en in alle windrigtings plaas.

Volgens Banana (1981:97) moet die groot bydrae wat Afrika tot die antropologiese besinning kan maak, in sy kollektivistiese benadering gesoek word:

(The church) should discard the individualistic ethic of Western culture and emphasize the collectivism found in African culture. This ethic is the fountain of hope for all future generations. It will be Africa's contribution to mankind.

\section{* Kontinuîteit}

Hierdie aspek hang ten nouste met al die voorafgaande saam: die een lewe van gemeenskap sit homself na die dood voort; daar is lewendige kontak tussen die 
lewendes en die 'dooies' (Mbiti, 1970:267-268; 1977:123-125); die nou-lewendes het 'n ewige kommunikasie met die tydloos-lewendes (Banana, 1991:22, 28). Wanneer 'n afgestorwe voorvader nie langer aktiewe verhoudings met die agtergeblewenes kan handhaaf nie, is hy 'algeheel dood' en raak hy in vergetelheid; eintlik

$\ldots$ is die heengeganes nie dood nie, hulle het net onsigbaar geword en hulle is weer in die lewendes aanwesig soos die lewendes in die ongeborenes. So het die mens homself dan onsterflik gemaak. Hy lewe nou in ewigheid, want selfs wanneer die verste ontslapenes in vergetelheid wegsink, word hul magiese lewenskwaliteite in die linie langs terug(ge)gee tot by die ongeborenes (Pretorius, 1977:10).

Wat egter aan die Afrikaan totaal onbekend is, is die opstanding van die liggaam (Mbiti, 1970:265; Banana, 1991:108).

Hoewel daar beweer word dat die Afrikaan in twee-dimensionele tydsbegrip (verlede en hede) daarop nahou, met 'n gevolglike onderontwikkelde toekomsperspektief (Oosthuizen, 1978:257-260, Van der Walt, 1990:30, 32, 40-41), blyk ook uit hierdie aspek dat in die Afrikadenke tyd meer met mense as met momente te maak het (Banana, 1991:24-25).

\subsection{Slotopmerkings}

Wanneer die hoofkenmerke van die Afrika-mensbeskouing van nader beskou word, is dit gou duidelik dat daar enersyds baie waardevolle aspekte aanwesig is maar andersyds ook problematiese aspekte na vore kom. Die beskouing dat die ganse lewe religieus bepaald is, dat die lewe een geheel vorm en dat gemeenskap (mededeelsaamheid) ' $n$ wesentlike deel daarvan vorm, moet positief waardeer word. Hierdie beskouing kan 'n belangrike korrektief wees teenoor 'n intellektualistiese, individualistiese en dualistiese Westerse benadering. Natuurlik moet verreken word dat hierdie waardering in ' $n$ groot mate formeel van aard is, aangesien die religieusiteit, heelheid en gemeenskap waarvan hier sprake is binne die Afrikadenke funksioneer en nie 'n Skriftuurlike inhoud het nie. Hierdie waardevolle kenmerke is dus nie sonder meer goed nie: dit moet trouens beskou word as 'n reaksie op God se skeppingsopenbaring (Van der Walt, 1988:13) en nie op sy Skrif- en Christusopenbaring nie. Reformatories beskou, moet die Afrika-mensbeskouing in die Bybelse mensbeskouing ingedoop en vanuit die Christologie en pneumatologie getransformeer word voordat dit volledig aan die koninkryk van God diensbaar kan wees. (Hierdie saak hang natuurlik saam met vrae oor die verhouding tussen evangelie en konteks, kerk en kultuur (akkommodasie of kontekstualisasie, sintese of antitese) - vrae wat in die sendingwetenskap veel diskussie uitgelok het. Aangesien dit 'n onderwerp van sy eie is, word dit hier sonder verdere bespreking slegs in die verbygaan genoem en daar gelaat.) 
Die homo Africanus vertoon egter ook 'n aantal negatiewe aspekte. Die swaar aksent op kommuniteit/kommunalisme is nie 'n ongemengde seën nie. Groepsverbondenheid bring mee dat eerder aan die waarheid (en eerlikheid) te kort gedoen sal word as om die groep te na te kom (vgl. Eks. 23:2; Num. 13-14). Groepsdenke en groepsoptrede bring dikwels grootskaalse intimidasie mee. Persoonlike individualiteit, inisiatief en verantwoordelikheid bly in die slag, dikwels met uiters nadelige gevolge vir die beroeps- en sakelewe. Die Afrikatydsbeskouing veroorsaak maklik tydsaamheid en traagheid omdat daar 'altyd nog tyd is om 'n ding te doen'.

Dat die Afrika-mensbeskouing as ' $n$ harmoniemodel getipeer is, beteken nie dat die Afrikaan geen geweld ken en pasifisties van aard is nie. Die talle stam-, etniese en nasionale oorloë wat op die vasteland van Afrika voorgekom het, en steeds voorkom, weerspreek so 'n gedagte (vgl. slegs die uitbreidingsoorloë wat deur die Zulu-koning, Shaka, gedurende die negentiende eeu in Suider-Afrika gevoer is) (vgl. Edgecombe, 1991:118-121). Die kenmerke wat opgesom is, is dus veelal kenmerke wat hulle binne 'n bepaalde gemeenskap in vredestyd laat ken. Die Afrikamens is nie onbekend met konflik en geweld nie. Die sondeval het immers nie by Afrika verbygegaan nie.

Juis dit is 'n groot leemte in die Afrika-antropologie: die sondebeskouing is te vlak en te menssentries: sonde word nie gesien as eerstens sonde teen Gód, en dus anti-goddelik nie (vgl. Ps. 51:6), maar as anti-menslik en anti-sosiaal. Sonde word ook nie in die aard van die daad gesoek word nie maar in die gevolge wat daaruit voortvloei. Sonde is ook nie sonde solank dit verborge bly nie; eers as sonde openhaar geword het, word dit as sonde erken. Hierdie sondebeskouing moet in die lig van die Bybelse getuienis as te oppervlakkig getipeer word (vgl. Van Rooy, 1988:153).

Die eskatologie van die Afrikaan is spiritisties - en dualisties. Slegs die gees leef na die dood voort (en eintlik net vir solank die nageslag daardie gees kan onthou, want namate die gees deur die nageslag vergeet word, verdwyn dit in die vergetelheid). Die opstanding van die liggaam is aan die tradisionele Afrika-denke vreemd.

Inderdaad, Afrika kan sonder die kruis en opstanding van Jesus Christus nie gered word nie en sonder die vemuwing van die Heilige Gees nie die koninkryk van God beerwe nie 
